\title{
A Weighted Sum of Multi-Objective Function based Reliability Analysis with the Integration of Distributed Generation
}

\author{
Sanjeeva kumar R A, Kavya Prayaga
}

\begin{abstract}
New trends in power system include the placement of the distributed generators (DGs) to overcome the drawbacks of the conventional power system, it can be connected near to the load points. Hence, the placement of DG is an important factor to be considered for the analysis due to its positive as well as negative impacts. An improved analytical approach for enhancing the reliability of the power system has been developed in this paper. By integrating DG of selected penetration level at all nodes of the test system, a set of reliability indices are evaluated based on interruption, improvement indices and blended as the multi-objective functions. Combinations of LVDI and PLRI with reliability improvement index are calculated by selecting the blended indices. Hence, enhanced system reliability is achieved. The analysis is carried out under the MATLAB platform on the standard RTBS bus distribution system.
\end{abstract}

Keywords: Distributed Generation, Reliability, multi-objective function, power loss reduction index.

\section{INTRODUCTION}

The electrical distribution network has been affected by disturbances and failures due to environmental as well as human issues. The invention of DG enhances the reliability of the system by improving the energy supplied [1]. This is advantageous to the services where the interruption in energy is unacceptable, like in health and industrial sectors. The improvement in the reliability can be measured in terms of the reliability indices [2]. There are mainly two methods of evaluation- analytical and simulation. The reliability of the power system is calculated by using mathematical equations using different indices by fallowing a methodology that uses the input data [4]. In the analytical approach, the system is represented by the simplified mathematical models. The equations are derived and the reliability indices are calculated using simple mathematical solutions [3]. The system performance at the customer end was used for the reliability evaluation of the system. The capability to deliver the power uninterrupted is called as the reliability. The flow of power in distribution network as the continuity in the service is an important factor of consideration. This can be defined by, The average failure rate $\left({ }^{(} \lambda\right)$,

Revised Manuscript Received on March 16, 2020.

* Correspondence Author

Sanjeeva Kumar R A*, Assistant Professor, Department of E\&E, PDA College of Engineering. Karnataka

Kavya Prayaga, Department of E\&E, PDA College of Engineering. Karnataka

(C) The Authors. Published by Blue Eyes Intelligence Engineering and Sciences Publication (BEIESP). This is an open access article under the CC BY-NC-ND license (http://creativecommons.org/licenses/by-nc-nd/4.0/) average outage time (' $r$ ') and average annual unavailability or average annual outage time ('U') are the three basic load point data [6]. This data can be used to analyze the performance of the considered system.

\section{RELIABILITY INDICES EVALUATION PROCEDURE}

The reliability indices such as SAIDI, SAIFI, SAIVI, and ASAI in the system are evaluated by considering $\lambda_{i}$, $U_{i}$, and $r_{i}$ of all sections and laterals in the distribution system. In this section after identifying the above-said parameters, the unavailability of load point $\mathrm{L}$ is given by $\sum \lambda_{\mathrm{i}}$ is calculated as shown below,

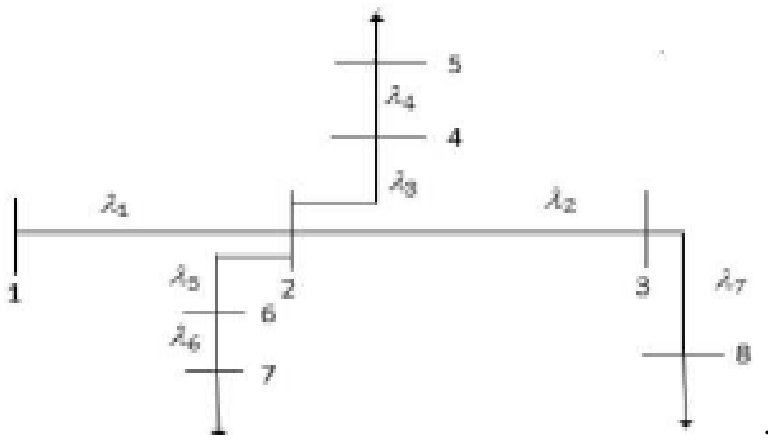

Fig 1. Typical Distribution circuit

$$
\begin{aligned}
& \lambda_{\mathrm{L} 2}=\lambda_{1} \\
& \lambda_{\mathrm{L} 3=} \lambda_{1+} \lambda_{2} \\
& \lambda_{\mathrm{L} 4=} \lambda_{1+} \lambda_{3} \\
& \lambda_{\mathrm{L} 5}=\lambda_{1+} \lambda_{3+} \lambda_{4} \\
& \lambda_{\mathrm{L} 6=} \lambda_{1+} \lambda_{5} \\
& \lambda_{\mathrm{L} 7=} \lambda_{1+} \lambda_{5+} \lambda_{6} \\
& \lambda_{\mathrm{L} 8=} \lambda_{1+} \lambda_{2+} \lambda_{7}
\end{aligned}
$$

Where $\lambda$ is a failure rate of line and $\lambda_{\mathrm{L}}$ represents the load point indices.

\section{A. Problem formulation}

The integration of DG at optimal location for selected level of penetration in this paper concentrates on the improvement of Reliability indices, Reduction of active power losses and Reduction of voltage deviation.

The calculation of load point reliability indices is as fallows

$$
\begin{gathered}
\lambda \mathrm{L}=\sum_{\mathrm{i}=0}^{\mathrm{n}} \lambda \mathrm{i}(1) \\
\mathrm{rL}=\frac{\sum_{\mathrm{i}=0}^{\mathrm{n}} \lambda \mathrm{i} \varphi \mathrm{r}}{\sum_{\mathrm{i}=0}^{\mathrm{n}} \lambda \mathrm{i}}
\end{gathered}
$$

Published By:

Blue Eyes Intelligence Engineering \& Sciences Publication 
A Weighted Sum of Multi-Objective Function based Reliability Analysis with the Integration of Distributed Generation

$$
\mathrm{UL}=\lambda \mathrm{L} * \mathrm{rL}
$$

Where

$i=$ feeder sections connecting the load points to the supply.

$\lambda_{\mathrm{q}}=$ Average failure rate at load point $\mathrm{L}$

$\mathrm{r}_{\mathrm{L}}=$ Average outage time at load point $\mathrm{L}$

$\mathrm{U}_{\mathrm{L}}=$ Average annual unavailability or average annual outage timeat load point $\mathrm{L}$

\section{B. System Average Duration Index (SAIDI)}

The average time of customers interrupted information can found by SAIDI

$\mathrm{SAIDI}=\frac{\sum_{\mathrm{i}=0}^{\mathrm{n}} \text { Ui } * \text { Ni }}{\sum_{i=0}^{\mathrm{n}} \text { Ni }}$

\section{System Average Interruption Frequency Index (SAIFI)}

It is the average number of interruptions per customer per unit time also defined as the ratio of a total number of interruptions to the total number of customers served.

$$
\mathrm{SAIFI}=\frac{\sum_{\mathrm{i}=0}^{\mathrm{n}} \lambda \mathrm{i} * \mathrm{Ni}}{\sum_{\mathrm{i}=0}^{\mathrm{n}} \mathrm{Ni}}
$$

\section{Average Service Unavailability Index (ASUI)}

It is the ratio of service availability of a total number of customer hours during a year to the customer hour demanded.

$A S A I=\frac{\sum_{i=0}^{n} N i * 8760-\sum_{i=0}^{n} U i * N i}{\sum_{i=0}^{n} N i * 8760}$

$\mathrm{Ni}=$ number of customers at load point $\mathrm{I}, \mathrm{i}=1,2,3$, , , , , $\mathrm{n}$

$\lambda \mathrm{i}=$ failure rate at load point $\mathrm{I}, \mathrm{i}=1,2,3,,,, \mathrm{n}$

$\mathrm{Ui}=\lambda^{*} \mathrm{r}$, where $\mathrm{r}$ is the outage time and 8760 is the number of hours in a calendar year.

\section{TO FIND THE OPTIMAL LOCATION OF DG}

The best location of DG has been chosen based on the multi-objective function, which gives the least Blended Index, Three different cases to improve the reliability indices are considered as follows

Optimal DG Placement for Reduction of Voltage deviation, Power loss, and Improvement of SAIFII

$\mathrm{BI}=\mathrm{w} 1 * \mathrm{LVDI}+\mathrm{w} 2 *$ PLRI $+\mathrm{w} 3 *$ SAIFII

Where,

$$
\begin{aligned}
& \text { LVDI }=\text { Log10 } * \frac{V_{D G}}{V_{\text {Base }}} \\
& \text { PLRI }=\frac{\text { Plass Base }_{\text {Tass DG }}}{\text { Plass Base }_{\text {Bas }}} \\
& \text { SAIFII }=\frac{\text { SAIFII }_{\text {Base }}-\text { SAIFII }}{\text { SAIF II }_{\text {Base }}}
\end{aligned}
$$

W1, W2, and W3 are the weighting factors for LVDI, PLRI and Reliability indices respectively,

$\mathrm{W} 1+\mathrm{W} 2+\mathrm{W} 3=1$

LVDI= Logarithmic Voltage Deviation Index,
Voltage Base $=$ Base Case Voltage in Volts

Voltage Dg= Voltage after Installation of DG in Volts, PLRI = Real Power Loss Reduction Index Ploss DG = Active Power Losses with DG in KW SAIVI= System Average Interruption Frequency index, SAIVII $=$ System Average Interruption Frequency improvement index, BI= Blended Index.

\section{TO FIND THE OPTIMAL SIZE OF DG}

The penetration level of DG is chosen based on the following equation.

$$
P L D G \%=\frac{\text { Size of DG }}{\text { Total demand }} * 100
$$

Where,

PLDG $=$ penetration level of DG

\section{PROCEDUCRE FOR DG INTEGRATION}

Step 1: Select and fetch the data of the test system.

Step 2: Calculate the actual size of DG for a selected penetration level using eq 11.

Step 3: Select and Compute the weighted sum of the multi-objective function index (WMOFI) by penetrating DG at each individual bus of the test system and rank indices on all buses.

Step 4: Choose the bus with minimum value of WMOFI as the optimal (best) location of DG.

Step 5: The above steps are repeated for different selected penetration levels of DG with relevant WMOFI.

\section{RESULTS AND DISCUSSIONS}

The RBTS 2 consists of 5 load bus bars (BUS2-BUS6). Bus2 and Bus4 are considered for the analysis. Bus 2 is having its generation integrated with it and Bus4 don't have any generation units connected which permits the effects and difference from generation and transmission system on the overall load point indices to be seen

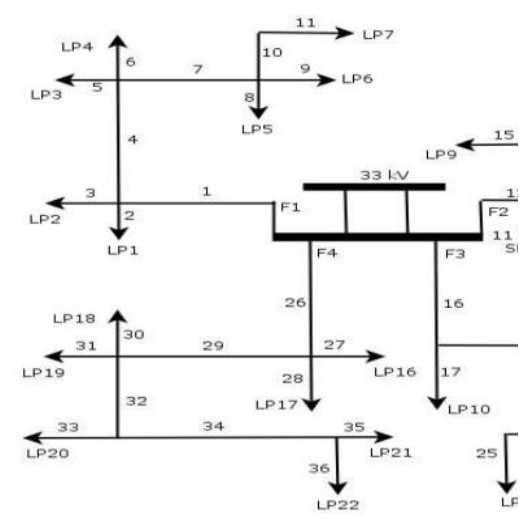

Fig 2: RBTS BUS 2

Published By:

Blue Eyes Intelligence Engineering \& Sciences Publication 


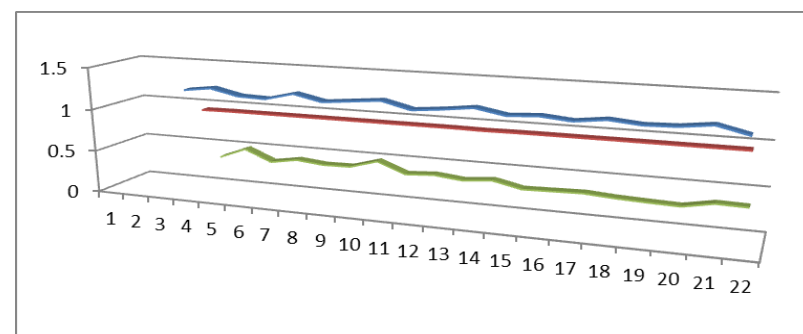

Fig 1:Voltage Profiles at Different Penetration levels of DG of RBTS BUS 2

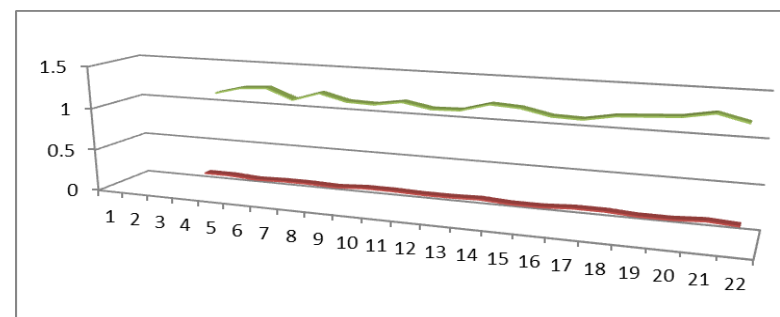

Fig 2: Losses at different Penetration levels of DG of RBTS BUS2

Voltage and power loss profiles, PLRI and Values of different reliability indices at Different Penetration levels of DG for Standard RTBS BUS RDS are shown figures 2,3 and 4 respectively.

Table 1: Values of different Reliability indices at $50 \%$

\begin{tabular}{|c|r|r|r|r|r|r|}
\hline \multirow{2}{*}{$\begin{array}{c}\text { Load } \\
\text { Point }\end{array}$} & \multicolumn{7}{|c|}{ At 50\% DG Penetration } \\
\cline { 2 - 7 } & PLRI & \multicolumn{1}{c|}{ LVDI } & SAIFI & SAIDI & ASAI & \multirow{2}{*}{ BIA } \\
\hline 1 & 0.67973 & 0.00198 & 0.21 & 1.13 & 0.9956 & 0.2551 \\
\hline 2 & 0.8228 & 0.0044 & 0.21 & 1.21 & 0.9995 & 0.30018 \\
\hline 3 & 0.69085 & 0.00487 & 0.19 & 1.23 & 0.9996 & 0.28593 \\
\hline 4 & 0.79456 & 0.00018 & 0.2 & 1.11 & 0.9996 & 0.29402 \\
\hline 5 & 0.51449 & 0.01168 & 0.2 & 1.21 & 0.9996 & 0.22263 \\
\hline 6 & 0.67657 & 0.00999 & 0.19 & 1.13 & 0.9996 & 0.27423 \\
\hline 7 & 0.92368 & 0.00853 & 0.21 & 1.12 & 0.9996 & 0.32327 \\
\hline 8 & 0.53236 & 0.01701 & 0.21 & 1.17 & 0.9995 & 0.21728 \\
\hline 9 & 0.56612 & 0.01906 & 0.2 & 1.11 & 0.9999 & 0.21612 \\
\hline 10 & 0.82456 & 0.01416 & 0.2 & 1.12 & 0.9996 & 0.30519 \\
\hline 11 & 0.5101 & 0.0196 & 0.21 & 1.21 & 0.9956 & 0.20633 \\
\hline 12 & 0.5801 & 0.02213 & 0.19 & 1.19 & 0.9995 & 0.24303 \\
\hline 13 & 0.54091 & 0.01403 & 0.19 & 1.12 & 0.9996 & 0.23935 \\
\hline 14 & 0.45283 & 0.02187 & 0.21 & 1.11 & 0.9996 & 0.17032 \\
\hline 15 & 0.65404 & 0.02001 & 0.21 & 1.17 & 0.9996 & 0.24726 \\
\hline 16 & 0.44048 & 0.01618 & 0.19 & 1.19 & 0.9996 & 0.20224 \\
\hline 17 & 0.53273 & 0.00367 & 0.19 & 1.21 & 0.9996 & 0.23386 \\
\hline 18 & 0.70169 & 0.00328 & 0.21 & 1.27 & 0.9996 & 0.2562 \\
\hline 19 & 0.68107 & 0.00418 & 0.19 & 1.19 & 0.9999 & 0.28637 \\
\hline 20 & 0.59052 & 0.00311 & 0.19 & 1.19 & 0.9995 & 0.24764 \\
\hline 21 & 0.54512 & 0.00076 & 0.21 & 1.25 & 0.9995 & 0.21122 \\
\hline 22 & 0.83649 & 0.00047 & 0.2 & 1.31 & 0.9995 & 0.32986 \\
\hline
\end{tabular}

Table 2 and 3 show the values of different reliability indices and corresponding power losses, powerloss reduction index and algorithmic voltage deviation index values at all the load points for $50 \%$ and $75 \%$ of DG penetration respectively. Values of Blended index (BI) at all the load points are shown from which the optimal location of DG will be decided at the minimum value bus.
Table 2: Values of different Relaibility indices at $\mathbf{7 5 \%}$

\begin{tabular}{|c|c|r|r|r|r|r|}
\hline \multirow{2}{*}{ Load Point } & \multicolumn{6}{|c|}{ At 75\% DG Penetration } \\
\cline { 2 - 7 } & \multicolumn{1}{|c|}{ PLRI } & \multicolumn{1}{c|}{ LVDI } & \multicolumn{1}{c|}{ SAIFI } & \multicolumn{1}{c|}{ SAIDI } & \multicolumn{1}{c|}{ ASAI } & \multicolumn{1}{l|}{ BIA } \\
\hline 1 & 0.667468 & 0.002764 & 0.2 & 1.01 & 0.9956 & 0.268295 \\
\hline 2 & 0.81179 & 0.002994 & 0.2 & 1.01 & 0.9995 & 0.313027 \\
\hline 3 & 0.553788 & 0.005755 & 0.18 & 1.11 & 0.9996 & 0.262067 \\
\hline 4 & 0.757384 & 0.000672 & 0.19 & 0.99 & 0.9996 & 0.300235 \\
\hline 5 & 0.50628 & 0.012662 & 0.19 & 1.12 & 0.9996 & 0.237218 \\
\hline 6 & 0.637249 & 0.011247 & 0.17 & 1.01 & 0.9996 & 0.297726 \\
\hline 7 & 0.818622 & 0.009616 & 0.2 & 0.98 & 0.9996 & 0.309051 \\
\hline 8 & 0.424248 & 0.025994 & 0.21 & 1.01 & 0.9995 & 0.185139 \\
\hline 9 & 0.537193 & 0.020044 & 0.19 & 0.99 & 0.9999 & 0.225712 \\
\hline 10 & 0.757113 & 0.015696 & 0.19 & 1.03 & 0.9996 & 0.30274 \\
\hline 11 & 0.482526 & 0.02112 & 0.2 & 1.01 & 0.9956 & 0.215302 \\
\hline 12 & 0.551168 & 0.024632 & 0.18 & 1.11 & 0.9995 & 0.252871 \\
\hline 13 & 0.531371 & 0.015722 & 0.18 & 1.03 & 0.9996 & 0.254214 \\
\hline 14 & 0.425384 & 0.020012 & 0.19 & 1.01 & 0.9996 & 0.197829 \\
\hline 15 & 0.640412 & 0.021819 & 0.19 & 1.01 & 0.9996 & 0.277524 \\
\hline 16 & 0.411662 & 0.018279 & 0.17 & 0.97 & 0.9996 & 0.229461 \\
\hline 17 & 0.517746 & 0.001289 & 0.17 & 1.12 & 0.9996 & 0.263077 \\
\hline 18 & 0.685239 & 0.004293 & 0.19 & 1.03 & 0.9996 & 0.285407 \\
\hline 19 & 0.668781 & 0.000467 & 0.17 & 1.02 & 0.9999 & 0.315171 \\
\hline 20 & 0.561743 & 0.004746 & 0.17 & 1.01 & 0.9995 & 0.274281 \\
\hline 22 & 0.807739 & 0.00612 & 0.19 & 1.01 & 0.9995 & 0.338989 \\
\hline
\end{tabular}

Table 3: Summary of results with different penetration levels of DG for CASE-B of RBTS BUS 2

\begin{tabular}{|c|c|c|c|c|}
\hline \multirow[t]{3}{*}{ Load Points } & \multirow[t]{3}{*}{ Number of customers } & \multirow[t]{3}{*}{ Base case } & \multirow{2}{*}{\multicolumn{2}{|c|}{ Penetration Level }} \\
\hline & & & & \\
\hline & & & $50 \%$ & $75 \%$ \\
\hline 1 & 210 & 0.9866 & 0.9911 & 0.9911 \\
\hline 2 & 210 & 0.9831 & 0.9836 & 0.9836 \\
\hline 3 & 210 & 0.9745 & 0.9855 & 0.9855 \\
\hline 4 & 1 & 0.9692 & 0.9696 & 0.9696 \\
\hline 5 & 1 & 0.9498 & 0.9757 & 0.9757 \\
\hline 6 & 10 & 0.9453 & 0.9673 & 0.9673 \\
\hline 7 & 10 & 0.9424 & 0.9611 & 0.9611 \\
\hline 8 & 1 & 0.9361 & 0.9735 & 0.9735 \\
\hline 9 & 1 & 0.9294 & 0.9711 & 0.9711 \\
\hline 10 & 210 & 0.9293 & 0.9601 & 0.9601 \\
\hline 11 & 210 & 0.9271 & 0.9699 & 0.9699 \\
\hline 12 & 200 & 0.9219 & 0.9701 & 0.9701 \\
\hline 13 & 1 & 0.9196 & 0.9498 & 0.9498 \\
\hline 14 & 1 & 0.9182 & 0.9586 & 0.9586 \\
\hline 15 & 10 & 0.9161 & 0.9593 & 0.9593 \\
\hline 16 & 10 & 0.9142 & 0.9489 & 0.9489 \\
\hline 17 & 200 & 0.9423 & 0.9403 & 0.9403 \\
\hline 18 & 200 & 0.9362 & 0.9433 & 0.9433 \\
\hline 19 & 200 & 0.9301 & 0.9277 & 0.9277 \\
\hline 20 & 1 & 0.9191 & 0.9257 & 0.9257 \\
\hline 21 & 1 & 0.9183 & 0.9199 & 0.9199 \\
\hline 22 & 10 & 0.9161 & 0.9171 & 0.9171 \\
\hline Total num & $r$ of customers affected & 1277 & 655 & 644 \\
\hline
\end{tabular}

Table 4 :Summary of results with different penetration levels of DG.

\begin{tabular}{|l|l|l|l|} 
DG Penetration & Base case & $50 \%$ & $75 \%$ \\
\hline Location of DG & & 14 & 8 \\
\hline Size of DG(in kW) & & 0.236 & 0.472 \\
\hline Bus number Affected & $5-22$ & $13-22$ & $13,16-22$ \\
\hline No of affected customers & 1277 & 644 & 623 \\
\hline Losses & 0.734 & 0.33 & 0.31 \\
\hline PLRI & 0.6677 & 0.45283 & 0.424248 \\
\hline LVDRI & 0.00276 & 0.02187 & 0.025994 \\
\hline SAIDI & 1.29550 & 1.11 & 1.01 \\
\hline ASAI & 0.9996 & 0.9996 & 0.9995 \\
\hline BI & 0.2973 & 0.17032 & 0.185139 \\
\hline
\end{tabular}

From table 5 it is clear that with the integration of DG at the optimal location with different penetration levels will reduce the number of customers getting affected by the voltage sag and their voltage profile at load points from a specified value of 0.96 p.u. 


\section{A Weighted Sum of Multi-Objective Function based Reliability Analysis with the Integration of Distributed Generation}

In the base case without DG integration the number of customers getting affected by voltage sag is 1277 and with $50 \%$ and $75 \%$ of DG penetration, the customers getting affected by voltage sag will be reduced to 644 and $623 \mathrm{y}$. From table 5 it is clear that with the integration of DG at the optimal location with different penetration levels will reduce the number of customers getting affected by the voltage sag and their voltage profile at load points from a specified value of 0.96 p.u.

\section{CONCLUSION}

An improved analytical approach for enhancing the reliability of the power system is developed in this paper. By integrating DG of selected penetration level at all nodes of the test system, a set of reliability indices including indices based on interruption, improvement indices and blended indices including the combination of LVDI and PLRI with reliability improvement index are calculated selecting the blended indices as the multi-objective functions. For each function (BI-A) all the indices are calculated which gives the number of customers affected in the system. The minimum number of customer affected with $75 \%$ penetration of DG is 644 . The system average voltage buses below 0.96 are considered and calculated to show the total number of customers affected by the voltage sag. Hence, enhanced system reliability is achieved.

\section{REFERENCES}

1. R Billington And R N Allan, Reliability Evaluation Of Power System, 2nd Edition, Berlin, Germany, Springer-Verlag

2. A H Etemadi And M Fotuhi Firuzabad, "Distributed System Reliability Enhancement Using Optimal Capacitor Placement," Iet Generation Trans. And Distr., Vol2, No.5, Pp 621-631, Sep 2008

3. D Elmakis, "New Computational Method In Power System Reliability", Berlin, Germany: Springer Verlag, 2000

4. R Allan And R Billington, "Probabilistic Assessment Of Power Systems," Proc Ieee, Vol88, Pp140-162, 2000

5. PM Costa And Ma Matos, "Assessing The Contribution Of Microgrids To The Reliability Of The Distributed Networks," Elect Power System Res, Vol79, No2, Pg 382-389

6. A Volkanovski, M Cepin And B Avko, "Application Of The Fault Tree Analysis For Assessment Of Power System Reliability,” Rel. Eng. Syst. Safety, Vol 27, Pg 721-736, 1999

7. T F T Sao And H C Chang, “ Comparative Case Studies For Value-Based Distribution System Reliability Planning," Elec, Power. Syst. Res., March 2004

8. R Gupta And L Goel, "Reliability Impact Of Sub Transmission And Radial Configuration On The Distribution System”, Elect. Mach. Power. Syst., 1999

9. C T Su And G R Lii, "Reliability Design Of Distribution System Using Modified Genetic Algorithm," Elec Power Syst Res., Jan 2002

10. AA Chowdary And D E Custer, "A Value-Based Probabilistic Approach To Design Urban Distribution System “, Ijeps, 2005, Vol

\section{AUTHORS PROFILE}

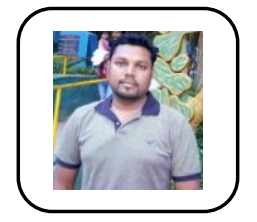

Sanjeeva Kumar R A, Received his Ph.D in the field of Power system., Master in power system and bachelor degree in Electrical and electronics from Visvesvaraya technological university in 2019, 2008 and 2006 respectively. He is currently working as Assistant Professor in department of E\&E at PDA College of Engineering. With the previous experience of working as Assistant professor from 2010 to 2014 at SDMIT Ujire, Worked as operation and maintenance engineer in industry from 2006 to 2008. Having 10 international journal publications and 06 conference proceedings.

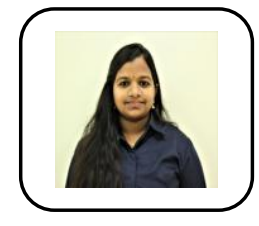

Kavya Prayaga, Received her Master in power system and bachelor degree in Electrical and electronics from Visvesvaraya technological university in 2018 and 2016 respectively. Received Silver medal at UG Level. She is currently working in OSI Bangalore, She is having publication of 2 international journals and 3 national conference proceedings. She has received Best paper award in national conference held at GSSSIT Mysore in 2018 and Best paper award at CMRIT Bangalore in Student competition 'SHRISTI' organized by state government in 2016. 